\title{
METÓDOS DE CUSTEIO: OS PERFIS DOS ARTIGOS PUBLICADOS NOS CONGRESSOS CUSTO, ANPCONT E USP
}

\author{
METHODS OF COST: THE PROFILES OF THE ARTICLES PUBLISHED IN \\ CONGRESSOS CUSTO, ANPCONT AND USP
}

\section{Recebimento: 2/10/2018 - Aceite: 30/06/2019 - Publicação: 31/07/2019 \\ Processo de Avaliação: Double Blind Review}

\author{
Ádria Tayllo Alves Oliveira ${ }^{1}$ \\ Mestre em Ciências Contábeis pela Universidade Federal da Paraíba (UFPB) \\ Professora da União de Ensino Superior de Campina Grande e da Universidade Estadual da \\ Paraíba \\ adriatayllo@gmail.com
}
Geraldo Nóbrega Borba Neto
Graduado em Ciências Contábeis pela União de Ensino Superior de Campina Grande neto.ap21@gmail.com

\author{
Danilo de Oliveira Aleixo \\ Doutor em Recursos Naturais pela Universidade Federal de Campina Grande (UFCG) \\ Professor da União de Ensino Superior de Campina Grande \\ daaleixo@uol.com.br
}

\section{RESUMO}

O objetivo deste artigo é identificar as tendências das publicações nos Congressos USP, ANPCONT e CBC que abordem métodos de custeio, entre o período de 2015 a 2017. A metodologia é qualitativa com o emprego da técnica bibliométrica, os dados coletados por meio dos websites sendo a analisados um universo de 779 artigos, categorizados em: quantidade de artigos publicados sobre contabilidade de Custos; quantidade de artigos publicados sobre métodos de custeios; tipologia dos métodos de custeios empregada em cada artigo; procedimentos científicos aplicados nos artigos sobre métodos de custeios. Os resultados encontrados evidenciaram que CBC, 8\% dos trabalhos apresentados em 2015 referiam-se aos Métodos de Custeio, em 2016 esse percentual foi de 12\%, e em 2017 de 15\%. No Congresso USP, apenas dois estudos discorriam sobre os métodos de custeio, enquanto

\footnotetext{
${ }^{1}$ Autor para correspondência: Universidade Federal da Paraíba: Campus I - João Pessoa - PB, Brasil. CEP: 58051-900.
}

Revista ENIAC Pesquisa, Guarulhos (SP), V.8, n.2, jul.- dez. 2019. 


\title{
REVISTA ENIAC PESQUISA
}

em 2016 e 2017 não foram identificados artigos que abordem os métodos de custeios. No Congresso ANPCONT, foram apresentados 118 artigos no ano de 2015, sendo que 12 haviam relação com o tema de Contabilidade de Custos e que nenhum trata efetivamente sobre os Métodos de Custeio. Conclui-se que CBC foi o congresso apresentou o maior número de artigos relacionados a essa temática de métodos de custeio, quando comparados com os Congressos USP e ANPCONT.

Palavras-chave: Contabilidade de custos. Método de custeio. Congressos.

\begin{abstract}
The objective of this article is to identify the trends of the publications in the Congresses USP, ANPCONT and CBC that address the costing methods, between the period of 2015 to 2017. The methodology is qualitative with the use of the bibliometric technique, the data collected through the websites being analyzed a universe of 779 articles, categorized in: quantity of published articles on accounting of Costs; number of published articles on costing methods; typology of the costing methods used in each article; applied in the articles on costing methods. The results showed that $C B C$, 8\% of the works submitted in 2015 referred to the Costing Methods, in 2016 this percentage was 12\%, and in 2017, 15\%. At the USP Congress, only two studies discussed costing methods, while in 2016 and 2017 articles were not identified that address costing methods. At the ANPCONT Congress, 118 articles were presented in the year 2015, of which 12 were related to the subject of Cost Accounting, none of which deals effectively with the Costing Methods. It is concluded that CBC was the congress presented the largest number of articles related to this issue of costing methods, when compared to the Congresses USP and ANPCONT.
\end{abstract}

Keywords: Cost accounting. Costing method. Congresses.

\section{INTRODUÇÃO}

A Revolução Industrial foi um fenômeno internacional, tendo acontecido de maneira gradativa, a partir de meados do século XVIII provocando mudanças importantes nos meios de produção, afetando diretamente os modelos econômicos e sociais de sobrevivência humana.

Neste período, a mão-de-obra direta e os materiais eram fatores decisivos interligados à produção, todavia, com o passar do tempo e as significativas modificações ambientais as corporações passaram a aplicar o capital, visando um aumento da capacidade produtiva inovadora e competitiva, que alcançasse um maior número de clientes. (MARTINS, 2010).

Assim, a Contabilidade de Custos, surge inicialmente para avaliação de estoques e apuração do resultado do período, posteriormente a Contabilidade de Custos passou a ser empregada no campo gerencial, auxiliando o controle e a tomada de decisão. Para SCHIER

Revista ENIAC Pesquisa, Guarulhos (SP), V.8, n.2, jul.- dez. 2019. 


\section{REVISTA ENIAC PESQUISA}

(2008, p.71), a "Contabilidade de Custos foi concebida como instrumento para resolução dos problemas da mensuração monetária dos estoques e do resultado das organizações, sendo num primeiro momento utilizado como ferramenta gerencial da admiração". Além de auxiliar na tomada decisão a contabilidade de custos fornece os dados detalhados sobre custos que a gestão precisa para controlar as operações atuais e planejar para o futuro (DERBECK E NAGY, 2001).

O custo é um gasto, isto é, como custos no momento da utilização de um produto ou na execução de um serviço (SCHIER, 2008). Para a mensuração e controle dos custos, foram elaborados métodos de custeio como ferramenta de geração de informações relevantes para a tomada de decisões.

Vários são os métodos de custeio, a exemplo do Custeio por absorção; custeio variável ou direto; ABC e Custeio padrão. Contudo, MARTINS e ROCHA (2010), afirmam que nenhum método de custeio atende a todas as necessidades informativas dos gestores dadas à complexidade do processo de administração das organizações.

Segundo GUEDES e BORSHIVER (2005), acreditam que à análise dos perfis dos trabalhos acadêmicos geram diferentes indicadores de produtividade, necessários ao planejamento, avaliação e gestão da ciência e da tecnologia, de uma determinada comunidade científica ou país, objetivando disseminação de discussões sobre o tema proposta. Para tanto, essa pesquisa estudada os principais congressos brasileiros na área de Contabilidade, sendo analisado o Congresso Brasileiro de Custos - CBC, Congresso de Controladoria e Contabilidade da USP e Congresso da Associação Nacional de Programas de Pós-graduação em Ciências Contábeis- ANPCONT.

Neste contexto, surge a seguinte questão de pesquisa: Como são os perfis das produções científicas acerca dos métodos de custeio, em artigos publicados nos Congressos USP, ANPCONT e CBC, no período de 2015 a 2017 ?

Esse estudo tem por objetivo identificar as tendências das publicações nos Congressos USP, ANPCONT e CBC que se refiram a métodos de custeio, com atenção específica voltada para os métodos absorção, variável, padrão e $\mathrm{ABC}$, nos principais congressos do país entre os anos de 2015 a 2017. Esse estudo justifica-se pela necessidade de fomentar as pesquisas relacionadas a métodos de custeio, principalmente a absorção, variável, padrão e $\mathrm{ABC}$, disseminando conhecimento sobre o tema. 


\section{REFERENCIAL TEÓRICO}

\subsection{CONTABILIDADE DE CUSTOS}

A Contabilidade é uma ciência social que estuda a riqueza patrimonial de modo individual, sob os aspectos quantitativos e qualitativos, tendo como principais objetivos o fornecimento de informações e a explicação dos fenômenos patrimoniais, favorecendo o controle, o planejamento e a tomada de decisão, no enfoque passado/presente/futuro.

A contabilidade de custo trata-se de uma ramificação da Contabilidade Geral de uma empresa ou entidade. Segundo DERBECK e NAGY (2001), a Contabilidade de custos fornece os dados detalhados sobre custos, do qual a gestão precisa para controlar as operações atuais e planejar para o futuro, proporcionando informações que permitem à gerência alocar recursos para as áreas mais eficientes e rentáveis da operação.

Para MARTINS (2003), a Contabilidade de Custos tem duas funções relevantes a de auxiliar o controle e de subsidiar as tomadas de decisões. No que diz respeito ao controle, este se refere ao fornecimento de dados para o estabelecimento de padrões e orçamentos, enquanto o auxílio na tomada de decisão ocorre no estágio imediatamente seguinte, por meio da comparação com os valores anteriormente definidos. Ressalta-se, ainda, que área de custo possui terminologia própria, que em muitas oportunidades, é utilizado de forma equivocada (SCHIER, 2008).

VICECONTI e NEVES (2013, p. 11), define gasto com a "renúncia de um ativo pela entidade com a finalidade de obtenção de um bem ou serviço, representada pela entrega ou promessa de entregar bens ou direitos (normalmente dinheiro)". Neste sentido, classificam-se gastos em: Investimentos, Custos ou Despesas, sendo:

a) Investimento: Gasto ativado em função de sua vida útil ou de benefícios atribuíveis a futuro (s) período (s) (MARTINS, 2003).

b) Custo: Gasto relativo à bem ou serviço utilizado no processo de produção de outros bens ou serviços (MARTINS, 2003).

c) Despesa: Gasto com bem ou serviço consumido direta ou indiretamente para a obtenção de receitas da entidade (SCHIER, 2008). 


\section{REVISTA ENIAC PESQUISA}

Os custos podem ser separados em diretos e indiretos; desta forma, HORNGREN, FOSTER e DATAR (1997), conceituam cada qual com sua característica, sendo os custos diretos aqueles relacionados a um determinado objeto de custo e que podem ser identificados com este de maneira economicamente viável (custo efetivo).

Custos diretos são os custos que podem ser identificados e quantificados no produto ou serviço e valorizados com relativa facilidade. Os materiais diretos, por exemplo, são normalmente requisitados com a identificação prévia de sua utilidade, ou seja, ao emitir a requisição para o almoxarifado, o responsável pela produção já indica, na requisição, o destino do material (SCHIER, 2008). Enquanto os indiretos são de difícil percepção ou designação por não estarem diretamente relacionados ao produto, necessitando de um critério de rateio para apropriá-los ao fabrico.

Assim, os custos indiretos são aqueles relacionados a um determinado objeto de custo, mas não podem ser identificados com este de maneira economicamente viável (custo efetivo) (HORNGREN, FOSTER E DATAR, 1997). São os custos que dependem de cálculos, rateios ou estimativas para serem apropriados aos diferentes produtos, portanto, são custos apropriados indiretamente aos produtos.

Quanto ao comportamento em relação a produtividade, a literatura classifica dois tipos de custos encontrados na maioria dos sistemas de custos, são os custos variáveis e custos fixos. Custos variáveis são aqueles “cujos valores se alteram em função do volume de produção da empresa [...] os custos variáveis aumentam à medida que aumenta a produção" (VICECONTI E NEVES, 2013, p. 18-19).

De acordo com HORNGREN, FOSTER e DATAR (1997), um custo variável é aquele que se altera em montante na proporção às alterações num direcionador de custo. Um direcionador de custos é qualquer fator que afeta os custos totais, ou seja, uma mudança no direcionador de custo resultará em uma alteração dos custos totais de um objeto de custo. Os exemplos mais comuns de custos variáveis são as matérias-primas, os materiais diretos e a mão-de-obra direta.

Custos fixos "são aqueles cujos valores são os mesmos qualquer que seja o volume de produção da empresa. [...] Os custos fixos são fixos em relação ao volume de produção, mas podem variar de valor no decorrer do tempo" (VICECONTI E NEVES, 2013, p. 18-19). O custo fixo é aquele que não se altera em montante apesar de alterações num direcionador de 


\section{REVISTA ENIAC PESQUISA}

custos, ou seja, não se altera com a variação da quantidade produzida. Eis alguns dos exemplos de custos fixos: seguro da fábrica, aluguel da fábrica, energia da fábrica etc.

\subsection{PRINCÍPIOS DE CUSTEIO}

O estudo sobre um sistema de custos pode ser feito a partir de dois pontos de vista: primeiramente o que enfoca o modo de como a informação gerada se adequa às necessidades da empresa, sendo denominado princípio de custeio. O outro enfoque está relacionado ao processamento dos dados para obtenção de informações, que é denominado método de custeio e os princípios de custeio são filosofias básicas que devem ser seguidas pelos sistemas de custos, de acordo com o objetivo e/ou período de tempo no qual se realiza a análise (BORNIA, 2009).

Assim, a literatura classifica os três os princípios de custeio, sendo eles: o custeio por absorção integral, custeio variável e custeio por absorção ideal. Para RIBEIRO (2009), define que o custeio por absorção integral como um sistema de custeio que contempla o custo de fabricação todos os custos incorridos no processo de fabricação do período, sejam eles diretos ou indiretos. Nesse caso somente as despesas integrarão o resultado do exercício.

BORNIA (2009) define o custeio por absorção integral ou total é quando todos os custos, sendo fixos ou variáveis, são distribuídos aos produtos. Esse princípio atende às exigências da contabilidade financeira para avaliação de estoques.

Sobre custeio variável e/ou direto WERNKE (2004), afirma que se trata de uma premissa básica do custeio direto onde são classificados com os custos claramente identificados com os produtos ou serviços vendidos (chamados de diretos ou variáveis) devem ser apropriados. Os demais custos necessários para manter a capacidade instalada (indiretos ou fixos) devem ser desconsiderados em termos de custo do produto.

O custeio variável ou direto consiste em atribuir aos produtos os custos variáveis, já os custos fixos são apropriados como custos do período. É uma ferramenta muito importante para a tomada de decisões no curto prazo (BORNIA, 2009). Corroborando com essa afirmação RIBEIRO (2009, p. 57), considera ser o custeio variável, “esse sistema contempla como custo de fabricação somente os custos diretos ou variáveis. Nesse caso, os custos indiretos integram o resultado juntamente com as despesas". 


\section{REVISTA ENIAC PESQUISA}

O custeio ideal trata-se, segundo BORNIA, (2009, p. 36), como o custeio por absorção ideal, todos os custos (fixos e variáveis) também são computados como custos dos produtos. Porém, custos relacionados com insumos de forma não eficiente (desperdícios) não são atribuídos aos produtos. $\mathrm{O}$ custeio por absorção ideal adapta-se particularmente ao auxílio do controle de custos e apoio ao processo de melhoria contínua da empresa. Os princípios de custeio, como dito anteriormente, são filosofias basilares a serem seguidas pelos sistemas de custos nas organizações.

\subsection{MÉTODOS DE CUSTEIO}

Os métodos são ferramentas utilizadas para determinar o valor dos objetos de custeio, reduzir custos, melhorar os processos, eliminar desperdícios, decidir entre produzir ou terceirizar e eliminar, criar e aumentar, ou diminuir, a linha de produção de certos produtos (ABBAS, GONÇALVES E LEONICE, 2012). Assim, os métodos de custeio são utilizados para alocação dos custos aos produtos e/ou serviços, são eles: Custeio por absorção; custeio variável ou direto; $\mathrm{ABC}$ e Custeio padrão.

a) Custeio por Absorção: Conforme HORNGREN, FOSTER e DATAR (1997), o custeio por absorção é o método de custeio do estoque no qual todos os custos de fabricação, variáveis e fixos, são considerados custos inventariáveis. O custeio por absorção é um método de custeio em que são apropriados aos produtos fabricados todos os custos incorridos sejam eles diretos, indiretos, fixos ou variáveis (CHERMAN, 2002).

É importante salientar que neste método, o custo separa-se das despesas; é aceito pela legislação societária (Lei 6.404/76, atualizada pela lei 11.638/2007) e, obedece aos princípios fundamentais de contabilidade, dentre eles, o princípio da realização da receita, confrontação e competência.

b) Custeio Variável: É o método de custeio de estoque, se traduz como aquele em que, todos os custos de fabricação variáveis são considerados custos inventariáveis enquanto todos os custos de fabricação fixos são excluídos dos custos inventariáveis, ou seja, são custos do período em que ocorrem (HORNGREN, FOSTER e DATAR, 1997). 


\section{REVISTA ENIAC PESQUISA}

Trata-se do custeio variável (ou direto), em que só são agregados aos produtos seus custos variáveis, considerando-se os custos fixos como se fossem despesas. Segundo MARTINS (2003), as demonstrações à base do custeio variável obtêm-se um lucro que acompanha sempre a direção das vendas, o que não ocorre com a absorção. Mas, por contrariar a competência e a confrontação, o custeio variável não é válido para balanços de uso externo, deixando de ser aceito tanto pela auditoria independente quanto pelo fisco. É fácil, entretanto, trabalhar-se com ele durante o ano e fazer-se uma adaptação de fim de exercício para se voltar à absorção.

c) Activity Based Costing (ABC): Este método de custeio é mais uma forma de alocar os custos indiretos de fabricação aos produtos: primeiro distribui as atividades por meio de um direcionador, posteriormente para os departamentos e finalmente para os produtos. $\mathrm{O} A B C$ é o método que obtém melhor afinidade com os custos indiretos, pois proporciona resultados mais próximos da realidade.

HORNGREN, FOSTER e DATAR (1997, p. 76) relatam o custeio baseado em atividades ( $\mathrm{ABC}$ ) como um prisma para se aperfeiçoar um sistema de custeio. Ele se concentra nas atividades como se fossem os principais objetos de custo. Uma atividade é um evento, tarefa ou unidade de trabalho com um determinado propósito.

$\mathrm{O}$ método $\mathrm{ABC}$ utiliza o custo dessas atividades como base para distribuir custos para outros objetos de custo tais como produtos, serviços ou clientes. Segundo o BORNIA (2009), existem quatro fases para calcular o custo dos produtos pelo ABC: (1) Mapeamento das atividades; (2) Distribuição dos custos às atividades; (3) Distribuição dos custos das atividades indiretas até as diretas; (4) Distribuição dos custos dos produtos. RIBEIRO (2009) acrescenta que o método $\mathrm{ABC}$ é um sistema de custeio que se caracteriza pela atribuição dos custos indiretos aos produtos por meio de atividades.

d) Custeio Padrão: O método de custeio padrão apropria os custos ligados à produção de bens ou serviços, pelo valor estimado, ou seja, uma estimativa do que deveriam ser não sendo considerado pelo valor real (VICECONTI E NEVES, 2013).

Assim, o custeio padrão é um custo estimado, isto é, calculado antes mesmo de iniciado o processo de fabricação, fundamentado sempre em custos de produções 


\section{REVISTA ENIAC PESQUISA}

anteriormente realizadas (RIBEIRO, 2009). Segundo CHERMAN (2002) o custo padrão é uma meta que a empresa deseja atingir em um determinado período de tempo. Todos os custos são tomados por estimativa.

Para execução do custeio padrão fazem-se necessárias os seguintes etapas: (1) fixar um custo padrão, o qual servirá de referência para a análise dos custos; (2) determinar o custo realmente incorrido; (3) levantar a variação (desvio) ocorrida entre o padrão e o real; e (4) analisar a variação, a fim de auxiliar a procura pelas causas (motivos) que levaram aos desvios. (BORNIA, 2009).

Desta forma, para obter o melhor resultado, deverá o gestor optar pelo método mais adequado às características operacionais de sua entidade, bem como, quais informações serão utilizadas para a tomada de decisão.

\section{PROCEDIMENTOS METODOLÓGICOS}

Esta pesquisa classifica-se com pesquisa descritiva, no qual segundo GIL (2008) as pesquisas descritivas possuem como objetivo a descrição das características de uma população, fenômeno ou de uma experiência.

Quanto à abordagem do problema, a pesquisa é qualitativa. As pesquisas qualitativas podem descrever a complexidade de determinado problema, analisar a interação de certas variáveis, compreender e classificar processos dinâmicos vividos por grupos sociais (RICHARDSON, 1999).

A técnica empregada nesse estudo foi a bibliométrica, que de acordo com GUEDES e BORSHIVER (2005), é uma ferramenta estatística que permite mapear e gerar diferentes indicadores de tratamento de gestão da informação e do conhecimento. Em conformidade com ARAÚJO (2006, p. 12), uma pesquisa bibliométrica consiste "na aplicação de técnicas estatísticas e matemáticas para descrever aspectos da literatura e de outros meios de comunicação (análise quantitativa da informação)".

O universo da pesquisa foram os congressos brasileiros, sendo analisados os anais do Congresso Brasileiro de Custos - CBC, Congresso de Controladoria e Contabilidade da USP e Congresso da Associação Nacional de Programas de Pós-graduação em Ciências Contábeis ANPCONT, com a finalidade de observar a evolução do tema propostos, haja vista, que tais

Revista ENIAC Pesquisa, Guarulhos (SP), V.8, n.2, jul.- dez. 2019. 


\section{REVISTA ENIAC PESQUISA}

congressos são de alto impacto acadêmico, sendo fontes de conhecimento e discussões sobre o tema pesquisado, ou seja, custos.

A coleta de dados ocorreu por meio dos websites de cada congresso, investigando os artigos publicados nos anais dos referidos congressos no período de 2015 a 2017. Assim sendo, foram analisados 779 artigos, do qual, 466 artigos publicados no CBC, 195 artigos no Congresso USP e 118 artigos no Congresso ANPOCONT. Ressalta-se também, que não foi possível realizar as análises dos artigos do Congresso ANPCONT no ano de 2016 e 2017, visto que, não foram disponibilizados no seu websiste.

Os dados coletados foram analisados principalmente os métodos de custeio absorção, variável, padrão e ABC. Além de serem observadas as seguintes características: (1) Quantidade de artigos publicados sobre contabilidade de Custos; (2) Quantidade de artigos publicados sobre métodos de custeios; (3) Tipologia dos métodos de custeios empregada em cada artigo; (4) procedimentos científicos aplicados nos artigos sobre métodos de custeios.

Os dados foram analisados de forma descritiva, cuja finalidade central é atingir o objetivo proposto de identificar as tendências das publicações nos Congressos USP, ANPCONT e CBC que se refiram a métodos de custeio, com atenção específica voltada para os métodos absorção, variável, padrão e $\mathrm{ABC}$, nos principais congressos do país entre os anos de 2015 e 2016.

\section{ANÁLISE DE RESULTADOS}

\subsection{CONGRESSO BRASILEIRO DE CUSTOS CBC}

O Congresso Brasileiro de Custos é o principal evento ligado à área de custos empresariais do Brasil, tendo como objetivos (1) debater o grande desafio da área de custos; (2) discutir a importância da gestão de custos nas relações interempresariais; (3) intensificar o desenvolvimento na área de gestão de custos no Brasil; (4) estabelecer uma ligação entre estudos acadêmicos e aplicações em organizações; (5) demonstrar quais são as dificuldades encontradas para a implantação de uma gestão de custos com enfoque em responsabilidade social, ambiental e corporativa, etc. (CBC, 2018).

Revista ENIAC Pesquisa, Guarulhos (SP), V.8, n.2, jul.- dez. 2019. 


\section{REVISTA ENIAC PESQUISA}

Neste sentido, a Tabela 01, apresentada abaixo, demonstra que 466 artigos foram trabalhos apresentados no Congresso Brasileiro de Custos no período 2015 a 2017, sendo que 150 trabalhos nos anos 2015 e 2016, enquanto no ano de 2017 foram publicados 166 artigos.

Tabela 01: Artigos publicados no CBC, período 2015 e 2017

\begin{tabular}{l|c|c|c|c|c|c}
\hline \multirow{2}{*}{$\begin{array}{c}\text { Artigos publicados no } \\
\text { CBC }\end{array}$} & \multicolumn{2}{|c|}{$\mathbf{2 0 1 5}$} & \multicolumn{2}{c|}{$\mathbf{2 0 1 6}$} & \multicolumn{2}{c}{$\mathbf{2 0 1 7}$} \\
\cline { 2 - 7 } & Frequência & Percentual & Frequência & Percentual & Frequência & Percentual \\
\hline $\begin{array}{l}\text { Trabalhos sobre } \\
\text { Contabilidade de Custos }\end{array}$ & 102 & 68 & 78 & 52 & 75 & 45 \\
\hline Trabalhos de demais áreas & 48 & 32 & 72 & 48 & 91 & 55 \\
\hline \multicolumn{1}{c}{ Total } & $\mathbf{1 5 0}$ & $\mathbf{1 0 0}$ & $\mathbf{1 5 0}$ & $\mathbf{1 0 0}$ & $\mathbf{1 6 6}$ & $\mathbf{1 0 0}$ \\
\hline
\end{tabular}

Fonte: Elaboração própria, 2018.

A Tabela 01 demostra a evolução das pesquisas cientificas publicadas no $\mathrm{CBC}$ ao longo de 3 anos; desta maneira, verifica-se a diminuição de artigos publicados no decorrer dos períodos analisados em frequência, uma vez que no ano de 2015, foram 102 artigos, enquanto em 2017 esse número foi de 75 trabalhos científicos. Isto posto, obteve-se uma redução no percentual apresentado na Tabela 01, que inicialmente era $68 \%$ (2015) e passou a ser de $45 \%$ (2017).

Tabela 02: Artigos publicados no CBC, sobre métodos de custeio

\begin{tabular}{l|c|c|c|c|c|c}
\hline \multirow{2}{*}{$\begin{array}{c}\text { Artigos publicados no } \\
\text { CBC }\end{array}$} & \multicolumn{2}{|c|}{$\mathbf{2 0 1 5}$} & \multicolumn{2}{c|}{$\mathbf{2 0 1 6}$} & \multicolumn{2}{c}{$\mathbf{2 0 1 7}$} \\
\cline { 2 - 7 } & Frequência & Percentual & Frequência & Percentual & Frequência & Percentual \\
\hline $\begin{array}{l}\text { Trabalhos sobre } \\
\text { Métodos de Custeio }\end{array}$ & 8 & 8 & 9 & 12 & 11 & 15 \\
\hline $\begin{array}{l}\text { Trabalhos de demais } \\
\text { áreas da Contabilidade } \\
\text { de Custos }\end{array}$ & 94 & 92 & 69 & 88 & 64 & 85 \\
\hline \multicolumn{1}{c}{ Total } & $\mathbf{1 0 2}$ & $\mathbf{1 0 0}$ & $\mathbf{7 8}$ & $\mathbf{1 0 0}$ & $\mathbf{7 5}$ & $\mathbf{1 0 0}$ \\
\hline
\end{tabular}

Fonte: Elaboração própria, 2018.

De acordo com Tabela 02 identificou-se que das pesquisas que abordavam a Contabilidade de Custos, quantas de fato, discorriam sobre os métodos de Custeio, assim foi possível verificar um crescimento nas publicações, haja vista que no ano de 2015 houve 8 trabalhos apresentados no $\mathrm{CBC}$, o que representa $8 \%$ dos artigos que tratavam sobre Contabilidade de Custos, no ano 2016 esse percentual foi de 12\%, e em 2017 de 15\%. Ressalta-se, ainda, que a maior parte das pesquisas de Contabilidade de Custos não aborda os métodos de custeio.

Quadro 1: Descrição dos artigos sobre métodos de custeio

Congresso Brasileiro de Custos 2015

Revista ENIAC Pesquisa, Guarulhos (SP), V.8, n.2, jul.- dez. 2019. 


\begin{tabular}{|c|c|c|c|}
\hline Autor (es) & Título & $\begin{array}{l}\text { Método de } \\
\text { custeio }\end{array}$ & Procedimento \\
\hline $\begin{array}{l}\text { Lima; Menegali; } \\
\text { Cittadin; Silva; } \\
\text { Guimarães e Giassi } \\
\text { (2015) }\end{array}$ & $\begin{array}{l}\text { Proposta de gerenciamento de custos por } \\
\text { meio do custeio por absorção: o caso de } \\
\text { uma entidade hospitalar beneficente do Sul } \\
\text { de Santa Catarina. }\end{array}$ & Absorção & Pesquisa- ação \\
\hline Xavier Filho (2015) & $\begin{array}{l}\text { Desenvolvendo tecnologia de gestão via } \\
\text { pesquisa-ação: Uma forma alternativa de } \\
\text { demonstrar o resultado tendo por base o } \\
\text { custeio variável. }\end{array}$ & Variável & Pesquisa- ação \\
\hline $\begin{array}{l}\text { Balzan e Dall’Agno } \\
(2015)\end{array}$ & $\begin{array}{l}\text { Gestão por atividades na pequena } \\
\text { propriedade rural: um estudo de caso } \\
\text { envolvendo a aplicação do Método de } \\
\text { Custeio ABC }\end{array}$ & $\mathrm{ABC}$ & Pesquisa- ação \\
\hline $\begin{array}{l}\text { Scanferla; Tonin; } \\
\text { Abbas e Marques } \\
\text { (2015) }\end{array}$ & $\begin{array}{l}\text { Estudo comparativo entre os métodos de } \\
\text { custeio por absorção aplicada no cultivo da } \\
\text { soja. }\end{array}$ & Absorção & Análise descritiva \\
\hline $\begin{array}{l}\text { Santos e Padrones } \\
\text { (2015) }\end{array}$ & $\begin{array}{l}\text { Método de Custeio Baseado em Atividades } \\
\text { para Educação Básica: uma proposta de } \\
\text { aplicação. }\end{array}$ & $\mathrm{ABC}$ & Análise descritiva \\
\hline Rosa e Conde (2015) & $\begin{array}{lrrr}\begin{array}{l}\text { Custo-padrão e } \\
\text { aplicado erçamento }\end{array} & \begin{array}{r}\text { empresarial } \\
\text { culturas }\end{array} \\
\text { temporárias. } & & & \\
\end{array}$ & Padrão & Análise descritiva \\
\hline $\begin{array}{l}\text { Santos; Oliveira e } \\
\text { Leite (2015) }\end{array}$ & $\begin{array}{l}\mathrm{O} \text { uso do método } \mathrm{ABC} \text { para apoio a } \\
\text { tomada de decisão em uma empresa do } \\
\text { setor alimentício }\end{array}$ & $\mathrm{ABC}$ & Análise descritiva \\
\hline $\begin{array}{l}\text { Mecca; Franzoi; Eckert } \\
\text { e Biasio (2015) }\end{array}$ & $\begin{array}{l}\text { Utilização do custo padrão como } \\
\text { ferramenta de auxílio aos gestores na } \\
\text { tomada de decisão }\end{array}$ & Padrão & Análise descritiva \\
\hline \multicolumn{4}{|c|}{ Congresso Brasileiro de Custos 2016} \\
\hline Autor (es) & Título & $\begin{array}{l}\text { Método de } \\
\text { custeio }\end{array}$ & Procedimento \\
\hline $\begin{array}{l}\text { Silva; Anzilago; Tonin } \\
\text { e Scarpin (2016) }\end{array}$ & $\begin{array}{l}\text { Estudo Comparativo entre os Métodos de } \\
\text { Custeio Absorção Aplicados na Produção } \\
\text { do Milho no Estado do Mato Grosso. }\end{array}$ & Absorção & Análise descritiva \\
\hline $\begin{array}{l}\text { Onçalves; Fe; Cunha; } \\
\text { Alemao; Gonçalves e } \\
\text { Braga (2016) }\end{array}$ & $\begin{array}{l}\text { A aplicação do Custeio Baseado em } \\
\text { Atividades para Conhecimento do Serviço } \\
\text { de Verificação de óbitos no Estado de } \\
\text { Minas Gerais. }\end{array}$ & $\mathrm{ABC}$ & Análise descritiva \\
\hline $\begin{array}{l}\text { Silva; Francisco; Cruz } \\
\text { e Bueno (2016) }\end{array}$ & $\begin{array}{l}\text { Custeio baseado em atividades: uma } \\
\text { proposta do seu uso no contexto de uma } \\
\text { Universidade Federal de Minas Gerais. }\end{array}$ & $\mathrm{ABC}$ & Análise descritiva \\
\hline $\begin{array}{l}\text { Vieira; Sausen; } \\
\text { Schreiber e Nora } \\
\text { (2016) }\end{array}$ & $\begin{array}{l}\text { Custeio baseado em atividades da } \\
\text { retaguarda operacional de uma instituição } \\
\text { financeira. }\end{array}$ & $\mathrm{ABC}$ & Análise descritiva \\
\hline $\begin{array}{l}\text { Siqueira; Mazzioni; } \\
\text { Gollo e Kruger (2016) }\end{array}$ & $\begin{array}{l}\text { Custeio por absorção x UEP: análise } \\
\text { comparativa dos custos em uma indústria } \\
\text { de confecções }\end{array}$ & $\begin{array}{c}\text { Absorção } \\
\text { e } \\
\text { UEP }\end{array}$ & Análise descritiva \\
\hline $\begin{array}{l}\text { Santos; Gadelha e } \\
\text { Leite (2016) }\end{array}$ & $\begin{array}{l}\text { Viabilidade do método } \mathrm{ABC} \text { para apoio a } \\
\text { tomada de decisão em pequenos negócios }\end{array}$ & $\mathrm{ABC}$ & Pesquisa-ação \\
\hline $\begin{array}{l}\text { Provenzano; } \\
\text { Cherobini; Pessin; } \\
\text { Souza e Machado } \\
\text { (2016) }\end{array}$ & $\begin{array}{l}\text { Análise da percepção dos docentes quanto } \\
\text { aos métodos baseados em atividades }\end{array}$ & $\mathrm{ABC}$ & Pesquisa-ação \\
\hline
\end{tabular}

Revista ENIAC Pesquisa, Guarulhos (SP), V.8, n.2, jul.- dez. 2019. 


\begin{tabular}{|c|c|c|c|}
\hline Maia e Morgan (2016) & $\begin{array}{l}\text { Implantação do sistema de informação de } \\
\text { contabilidade de custos: estudo de caso em } \\
\text { uma empresa prestadora de serviços de TI } \\
\text { que utiliza o ABC }\end{array}$ & $\mathrm{ABC}$ & Pesquisa-ação \\
\hline \multicolumn{4}{|c|}{ Congresso Brasileiro de Custos 2017} \\
\hline Autor (es) & Título & $\begin{array}{l}\text { Método de } \\
\text { custeio }\end{array}$ & Procedimento \\
\hline $\begin{array}{l}\text { Scardelato, Pavão e } \\
\text { Camacho (2017) }\end{array}$ & $\begin{array}{l}\text { Integração Entre Gestão dos Custos da } \\
\text { Qualidade e o Custeio Baseado em } \\
\text { Atividades: Um Estudo no Setor de } \\
\text { Controle de Qualidade em uma Empresa } \\
\text { do Ramo de Laticínios }\end{array}$ & $\mathrm{ABC}$ & Análise descritiva \\
\hline $\begin{array}{l}\text { Silva; Policário e } \\
\text { Deorce (2017) }\end{array}$ & $\begin{array}{l}\text { Aplicação do Método de Custeio Por } \\
\text { Absorção com Departamentalização em } \\
\text { um Salão de Beleza }\end{array}$ & $\begin{array}{l}\text { Absorção e } \\
\text { Departamentaliz } \\
\text { ação }\end{array}$ & Análise descritiva \\
\hline $\begin{array}{l}\text { Mazzuco; Wronski e } \\
\text { Zonatto (2017) }\end{array}$ & $\begin{array}{l}\text { Custeio Baseado em Atividades e Tempo } \\
\text { (TDABC): Um Estudo em uma Instituição } \\
\text { de Ensino Superior do Sul do Estado de } \\
\text { Santa Catarina }\end{array}$ & TDABC & Análise descritiva \\
\hline $\begin{array}{l}\text { Sanches, Britto, Silva e } \\
\text { Araújo (2017) }\end{array}$ & $\begin{array}{l}\text { Honorários Contábeis Calculados de } \\
\text { Acordo com o Custeio por Absorção: Uma } \\
\text { comparação com os valores efetivamente } \\
\text { cobrados por um escritório de } \\
\text { contabilidade no Distrito Federal }\end{array}$ & Absorção & Análise descritiva \\
\hline $\begin{array}{l}\text { Vichinheski, Bendlin, } \\
\text { Ferreira e Ferreira } \\
(2017)\end{array}$ & $\begin{array}{l}\text { Método de Custeio UEP - Unidade de } \\
\text { Esforço de Produção: estudo de caso em } \\
\text { uma indústria cerâmica do planalto norte } \\
\text { catarinense }\end{array}$ & UEP & Análise descritiva \\
\hline $\begin{array}{l}\text { Battini, Marian, Boff e } \\
\text { Pletsch (2017) }\end{array}$ & $\begin{array}{l}\text { Método de Custeio UEP: Aplicação em um } \\
\text { sistema de produção contínua }\end{array}$ & UEP & Análise descritiva \\
\hline $\begin{array}{l}\text { Souque e Müller } \\
(2017)\end{array}$ & $\begin{array}{l}\text { Sistema de Custeio para Comércio de } \\
\text { Cervejas por meio de Beer Truck }\end{array}$ & $\begin{array}{l}\text { Método do } \\
\text { Centro de } \\
\text { Custos }\end{array}$ & Análise descritiva \\
\hline $\begin{array}{l}\text { Batista; Assis; Cruz e } \\
\text { Bufoni (2017) }\end{array}$ & $\begin{array}{l}\text { Custeio Baseado em Atividades no } \\
\text { Serviço Público: Um estudo de caso na } \\
\text { Universidade Federal do Rio de Janeiro }\end{array}$ & $\mathrm{ABC}$ & Análise descritiva \\
\hline $\begin{array}{l}\text { Bendlin; Gomes e } \\
\text { Vichinheski (2017) }\end{array}$ & $\begin{array}{l}\text { Aplicação do Custeio Baseado em } \\
\text { Atividades - ABC no gerenciamento dos } \\
\text { custos conjuntos na atividade industrial de } \\
\text { beneficiamento e curtimento de couros }\end{array}$ & $\mathrm{ABC}$ & Análise descritiva \\
\hline $\begin{array}{l}\text { Souza; Castanha; } \\
\text { Monteiro; Milaneze e } \\
\text { Cittadin (2017) } \\
\end{array}$ & $\begin{array}{l}\text { O uso do Custeio ABC para formação do } \\
\text { preço de venda em um laboratório de } \\
\text { análises ambientais }\end{array}$ & $\mathrm{ABC}$ & Análise descritiva \\
\hline $\begin{array}{l}\text { Cunha; Monteiro; } \\
\text { Castanha; Menegali; } \\
\text { Vieira e Cittadin } \\
(2017)\end{array}$ & $\begin{array}{l}\text { O uso do custeio variável para gestão de } \\
\text { uma vinícola catarinense }\end{array}$ & Variável & Análise descritiva \\
\hline
\end{tabular}

Fonte: Elaboração própria, 2018.

No que se refere à descrição dos artigos difundidos no $\mathrm{CBC}$, o Quadro 01 demostra que 13 pesquisas aborda o Método de Custeio $\mathrm{ABC}$, seguido por Absorção com 6 artigos publicados. $\mathrm{O} A B C$ analisa o comportamento dos custos por atividade, independente da área

Revista ENIAC Pesquisa, Guarulhos (SP), V.8, n.2, jul.- dez. 2019. 


\section{REVISTA ENIAC PESQUISA}

da empresa, e estabelece relações entre atividades e o consumo de recurso afirma WERNKE (2004), ou seja, identifica quais atividades consome mais recursos.

Destaca-se, que 3 artigos apresentaram UEP, sendo esse, o Método de Custeio baseado na Unidade de Esforço de Produção. Todavia, os métodos menos empregados nas pesquisas são a variável e o Padrão.

Quanto ao procedimento metodológico, o Quadro 01 evidencia que 22 artigos desenvolveram pesquisas por meio de análise descritiva, enquanto apenas 6 deles possuem as características de pesquisa-ação, neste sentido, SCOTT (2002) define que pesquisa-ação busca solucionar problemas gerenciais e/ ou administrativos de forma sistemática, que quando necessário, sofrerá alterações ou intervenções do pesquisador, sendo combinado planejamento, ação, observação e reflexão.

\subsection{CONGRESSO USP DE CONTROLADORIA E CONTABILIDADE}

O Congresso USP de Controladoria e Contabilidade é um evento que tem por objetivo principal promover o intercâmbio de estudos e experiências, bem como a divulgação de ideias sobre a teoria e a prática da controladoria e da contabilidade, aproximando profissionais desse segmento e pesquisadores acadêmicos em momentos como apresentações de trabalhos, workshops, fóruns e palestras (USP, 2018).

Tabela 03: Artigos publicados no Congresso USP, período 2015 a 2017

\begin{tabular}{l|c|c|c|c|c|c}
\hline \multicolumn{1}{c|}{$\begin{array}{c}\text { Artigos publicados no } \\
\text { Congresso USP }\end{array}$} & \multicolumn{2}{|c|}{$\mathbf{2 0 1 5}$} & \multicolumn{2}{c|}{$\mathbf{2 0 1 6}$} & \multicolumn{2}{c}{$\mathbf{2 0 1 7}$} \\
\cline { 2 - 7 } & Frequência & Percentual & Frequência & Percentual & Frequência & Percentual \\
\hline $\begin{array}{l}\text { Trabalhos sobre } \\
\text { Contabilidade de Custos }\end{array}$ & 6 & 11 & 2 & 3 & & 1 \\
\hline Trabalhos de demais áreas & 51 & 89 & 61 & 97 & 74 & 99 \\
\hline \multicolumn{1}{c}{ Total } & $\mathbf{5 7}$ & $\mathbf{1 0 0}$ & $\mathbf{6 3}$ & $\mathbf{1 0 0}$ & $\mathbf{7 5}$ & $\mathbf{1 0 0}$ \\
\hline
\end{tabular}

Fonte: Elaboração própria, 2018.

A Tabela 03 demonstra que os trabalhos apresentados no período de 2015 a 2017, tantalizando 195 artigos, 11(onze) deles versam sobre contabilidade de custos. Nota-se que os percentuais de artigos publicados sobre o tema de Contabilidade de Custos, vêm diminuindo ao longo dos anos, visto que, em 2015 obteve-se um percentual de 11\% enquanto em 2017 e percentual passou a ser de $1 \%$.

Revista ENIAC Pesquisa, Guarulhos (SP), V.8, n.2, jul.- dez. 2019. 


\section{REVISTA ENIAC PESQUISA}

Tabela 04: Artigos publicados Congresso USP, sobre métodos de custeio

\begin{tabular}{c|c|c|c|c|c|c}
\hline \multirow{2}{*}{$\begin{array}{c}\text { Artigos publicados no } \\
\text { Congresso USP }\end{array}$} & \multicolumn{2}{|c|}{$\mathbf{2 0 1 5}$} & \multicolumn{2}{c|}{$\mathbf{2 0 1 6}$} & \multicolumn{2}{c}{$\mathbf{2 0 1 7}$} \\
\cline { 2 - 7 } & Frequência & Percentual & Frequência & Percentual & Frequência & Percentual \\
\hline $\begin{array}{l}\text { Trabalhos sobre Métodos } \\
\text { de Custeio }\end{array}$ & 2 & 18 & - & - & & - \\
\hline $\begin{array}{l}\text { Trabalhos de demais áreas } \\
\text { da contabilidade de custos }\end{array}$ & 9 & 82 & 2 & 100 & 1 & 100 \\
\hline \multicolumn{1}{c}{ Total } & $\mathbf{1 1}$ & 100 & $\mathbf{2}$ & $\mathbf{1 0 0}$ & $\mathbf{1}$ & $\mathbf{1 0 0}$ \\
\hline
\end{tabular}

Fonte: Elaboração própria, 2018.

Tratando-se do Congresso USP 2015, de acordo com o exposto na Tabela 04 e com a pesquisa realizada, foram encontrados 2 trabalhos sobre métodos de custeio, totalizando um percentual de 18\% (dezoito por cento) de artigos apresentados, de acordo com Tabela 04.

Salienta-se que nos anos de 2016 e 2017 não foram identificados artigos que abordassem os métodos de custeios, assim, essa redução pode ser justificadas por inúmeros fatores, contudo WEISS, BALTHAZAR, TRIERWEILLE (2008) enfatizam que os gestores têm grande dificuldade em perceber a importância da adoção de um sistema de custeio, essa falta de conhecimento por parte dos gestores podem delimita as pesquisas aplicadas nas companhias.

Quadro 2: Descrição dos artigos sobre métodos de custeio

\begin{tabular}{|c|c|c|c|}
\hline \multicolumn{4}{|c|}{ Congresso USP, período 2015} \\
\hline Autor(es) & Título & Método & Procedimento \\
\hline $\begin{array}{l}\text { SOUZA; COSTA } \\
(2015)\end{array}$ & $\begin{array}{l}\text { Complexidade Versus Viabilidade: Um } \\
\text { Estudo de Caso Sobre o ABC em Ambiente de } \\
\text { Estrutura Tecnológica Intensiva. }\end{array}$ & $\mathrm{ABC}$ & Análise descritiva \\
\hline $\begin{array}{l}\text { SILVA; LAY; } \\
\text { PAMPLONA e } \\
\text { ZONATTO (2015) }\end{array}$ & $\begin{array}{l}\text { Inconsciente Coletivo no Conhecimento de } \\
\text { Contabilidade de Custos: Uma Abordagem A } \\
\text { Partir da Psicologia Analítica de Jung e Os } \\
\text { Métodos de Custeio Variável e Por Absorcão. }\end{array}$ & $\begin{array}{l}\text { Variável } \\
\text { e } \\
\text { Absorcão }\end{array}$ & Pesquisa-Ação \\
\hline
\end{tabular}

Fonte: Elaboração própria, 2018.

No que se refere à descrição dos artigos apresentado no Congresso USP, o Quadro 02 demostra que dos 2 artigos, um abordava Método de Custeio $\mathrm{ABC}$, enquanto o outro artigo tratava dos Método de Custeio Variável e Absorção. Segundo WERNKE (2004), o Custeio Variável aloca os custos claramente identificados com os produtos ou serviços vendidos devem ser apropriados. Os demais custos necessários para manter a capacidade instalada devem ser desconsiderados em termos de custo do produto.

Destarte, é pertinente evidenciar que o Congresso USP nos anos de 2016 e 2017 não foi apresentado nenhum trabalho relacionado aos métodos de custeio em análise. Quanto ao 


\section{REVISTA ENIAC PESQUISA}

procedimento metodológico, o Quadro 02 evidencia que 1 artigo desenvolveu a pesquisa por meio de análise descritiva, enquanto no outro foi empregada a pesquisa-ação.

\subsection{CONGRESSO ANPCONT}

O Congresso ANPCONT é um evento acadêmico-científico da Associação Nacional de Programas de Pós-Graduação em Ciências Contábeis que proporciona a interação da comunidade acadêmica, pesquisadores, professores e estudantes, representando um meio de divulgação da produção técnico-científica na área das Ciências Contábeis (ANPCONT, 2018).

Tabela 04: Artigos publicados no Congresso ANPCONT, período 2015

\begin{tabular}{l|c|c}
\hline \multirow{2}{*}{ Artigos publicados no Congresso ANPCONT } & \multicolumn{2}{|c}{$\mathbf{2 0 1 5}$} \\
\cline { 2 - 3 } Trabalhos sobre Contabilidade de Custos & 12 & Percentual \\
\hline Trabalhos de demais áreas & 106 & 90 \\
\hline \multicolumn{1}{c|}{ Total } & $\mathbf{1 1 8}$ & $\mathbf{1 0 0}$ \\
\hline
\end{tabular}

Fonte: Elaboração própria, 2017.

Conforme a análise dos artigos do Congresso ANPCONT, foram apresentados 118 artigos no ano de 2015; entretanto, apenas 12 (doze) haviam relação com o tema de Contabilidade de Custos. Ainda assim, dos 12 artigos relacionados, nenhum deles tratava efetivamente sobre os Métodos de Custeio ora analisados de acordo com Tabela 04.

Ressalta-se que, nas observações realizada no website do Congresso ANPCONT nos 2016 e 2017 até o presente momento, não foram disponibilizados os artigos apresentados naquele ano para que pudesse ser feito um exame sobre os temas aqui discutidos.

\section{CONSIDERAÇÕES FINAIS}

O objetivo deste artigo é identificar as tendências das publicações nos Congressos USP, ANPCONT e CBC que se refiram a métodos de custeio, com atenção específica voltada para os métodos absorção, variável, padrão e ABC, entre o período de 2015 a 2017.

Assim, a metodologia é qualitativa com o emprego da técnica bibliométrica, os dados coletados por meio dos websites sendo a analisados 779 artigos, (1) Quantidade de artigos publicados sobre contabilidade de Custos; (2) Quantidade de artigos publicados sobre

Revista ENIAC Pesquisa, Guarulhos (SP), V.8, n.2, jul.- dez. 2019. 


\section{REVISTA ENIAC PESQUISA}

métodos de custeios; (3) Tipologia dos métodos de custeios empregada em cada artigo; (4) procedimentos científicos aplicados nos artigos sobre métodos de custeios.

No $\mathrm{CBC}$, verificou-se a diminuição de artigos publicados com a temática de Contabilidade de Custos, visto que, em 2015, foram 68\% dos artigos, enquanto em 2017 esse número foi de $45 \%$ trabalhos científicos. Além disso, identificou-se que $8 \%$ dos trabalhos apresentados em 2015 referiam-se aos Métodos de Custeio, em 2016 esse percentual foi de $12 \%$, e em 2017 de 15\%. Quanto ao método mais empregado nas pesquisas analisadas verificou que o Activity Based Costing (ABC), apresentavam-se em 22 trabalhos.

A pesquisa identificou que no Congresso USP os artigos publicados sobre o tema de Contabilidade de Custos vêm diminuindo ao longo dos anos, visto que, em 2015, obteve-se um percentual de 11\% enquanto em 2017 e percentual passou a ser de 1\%. Dos artigos examinados apenas 2 discorriam sobre os métodos de custeio. Salienta-se que nos anos de 2016 e 2017 não foram identificados artigos que abordem os métodos de custeios,

No Congresso ANPCONT foram apresentados 118 artigos no ano de 2015, sendo 12 haviam relação com o tema de Contabilidade de Custos, destes 12 artigos nenhum tratava efetivamente sobre os Métodos de Custeio. Enquanto isso os dados de 2016 e 2017 foram prejudicados, visto que não foram divulgados no website do Congresso ANPCONT.

O Congresso Brasileiro de Custo foi aquele que apresentou o maior número de artigos relacionados a essa temática. Todavia, por tratar-se de um congresso especificamente de custos, os números de artigos encontrados sobre os temas ora discutidos ainda demonstram quantidades mínimas comparando ao total de artigos apresentados sobre outros temas no mesmo congresso. A pesquisa apontou ainda que, dentre esses artigos, o método $\mathrm{ABC}$ foi o mais utilizado naqueles sobre métodos de custeio. Além disto, a maior parte desses artigos foi desenvolvida por meio de pesquisa dinâmica, com estudo de campo, entrevistas e questionários, enquanto que poucos foram analisados apenas por meio de leitura e análise de outros documentos sobre os temas.

Como limitação, este artigo se deparou com a impossibilidade de acesso a alguns dados, bem como delimitou-se em analisar 3 congressos, não sendo possível generalizar a pesquisa. Além disso, embora a relevância do tema tratado ainda seja escassa, sugere-se que novos estudos sejam elaborados com o objetivo de fomentar o assunto, numa perspectiva 


\section{REVISTA ENIAC PESQUISA}

temporal mais ampla e evolutiva para que haja a verificação da produção sobre o tema em uma escala que proporcione maiores números e dados.

\section{REFERÊNCIAS}

ABBAS, K.; GONÇALVES, M. N.; LEONCINE, M. Os métodos de custeio: vantagens, desvantagens e sua aplicabilidade nos diversos tipos de organizações apresentadas pela literatura. ConTexto, Porto Alegre, v. 12, n. 22, p. 145-159, $2^{\circ}$ semestre 2012.

BALZAN e DALL'AGNO. Gestão por atividades na pequena propriedade rural: um estudo de caso envolvendo a aplicação do Método de Custeio ABC. Anais... 2015. XXII Congresso Brasileiro de Custos, 2015.

BATISTA, A. P.; ASSIS, G. C. T de; CRUZ, C. F.; BUFONI, A. L. Custeio Baseado em Atividades no Serviço Público: Um estudo de caso na Universidade Federal do Rio de Janeiro. Anais... 2017. XXIV Congresso Brasileiro de Custos, 2017.

BATTINI, R.; MARIAN, S.; BOFF, M. L.; PLETSCH, C. S. Método de Custeio UEP: Aplicação em um sistema de produção contínua. Anais... 2017. XXIV Congresso Brasileiro de Custos, 2017.

BENDLIN, L.; GOMES, E. L.; VICHINHESKI, K. A. Aplicação do Custeio Baseado em Atividades - ABC no gerenciamento dos custos conjuntos na atividade industrial de beneficiamento e curtimento de couros. Anais... 2017. XXIV Congresso Brasileiro de Custos, 2017.

BORNIA, Antonio Cezar. Análise gerencial de custos: aplicação em empresas modernas. 2. ed. São Paulo: Atlas, 2009.

CHERMAN, Bernado C. Contabilidade de custos. Vem Concursos, 2002.

CONGRESSO ANPCONT. Disponível em: < http://anpcont.org.br/>. Acesso em: 20 de jan. de 2018.

CONGRESSO BRASILEIRO DE CUSTOS (CBC). Disponível em: <https://cbc2018.abcustos.org.br/> . Acesso em: 20 de jan. de 2018.

CONGRESSO USP DE CONTROLADORIA E CONABILIDADE. Disponível em:<

http://www.congressousp.fipecafi.org/Home/Index>.Acesso em: 20 de jan. de 2018.

CUNHA, P. M. C.; MONTEIRO, J. J.; CASTANHA, E. T.; MENEGALI, M. V.; VIEIRA, A. C. P.; CITTADIN, A. O uso do custeio variável para gestão de uma vinícola catarinense. Anais... 2017. XXIV Congresso Brasileiro de Custos, 2017.

Revista ENIAC Pesquisa, Guarulhos (SP), V.8, n.2, jul.- dez. 2019. 


\section{REVISTA ENIAC PESQUISA}

DERBECK, E. J. V.; NAGY, C. F. Contabilidade de custos. 11. ed. São Paulo: Thomson, 2001.

GIL, Antônio Carlos. Como elaborar projetos de pesquisa. 5. ed. São Paulo: Atlas, 2008.

GONÇALVES, M. A.; FE, B. P.; CUNHA, Y. F. F.; ALEMAO, M. M.; GONÇALVES, F. M. V.; BRAGA. L. C. A aplicação do Custeio Baseado em Atividades para Conhecimento do Serviço de Verificação de óbitos no Estado de Minas Gerais. Anais... 2016. XXIII Congresso Brasileiro de Custos, 2016.

GUEDES, V. L. S.; BORSCHIVER, S. Bibliometria: uma ferramenta estatística para a gestão da informação e do conhecimento em sistemas de informação, de comunicação e de avaliação científica e tecnológica. Anais... 2005. Encontro Nacional de Ciência Da Informação, Salvador, 2005.

HORNGREN, C. T.; FOSTER, G.; DATAR, S. M. Contabilidade de custos. 9. ed. Rio de Janeiro: LTC, p .717,1997.

SILVA, T. B. de J.; LAY, L. A.; PAMPLONA, E.; ZONATTO, V.C. da S.; Inconsciente Coletivo no Conhecimento de Contabilidade de Custos: Uma abordagem a partir da psicologia analítica de Jung e os métodos de custeio variável e por absorção. Anais... 2015. XV Congresso USP de Controladoria e Contabilidade, 2015.

LIMA, T. A.; MENEGALI, M. V.; CITTADIN, A.; SILVA, R. da; GUIMARÃES, M. L. F.; GIASSI, D. Proposta de Gerenciamento de Custos por meio do Custeio por Absorção: o caso de uma entidade hospitalar beneficente do Sul de Santa Catarina. Anais... 2015. XXII Congresso Brasileiro de Custos, 2015.

MAIA, S. H.; MORGAN, B. Implantação do sistema de informação de contabilidade de custos: estudo de caso em uma empresa prestadora de serviços de TI que utiliza o ABC. Anais... 2016. XXIII Congresso Brasileiro de Custos, 2016.

MARTINS, Eliseu. Contabilidade de custos. 9 ed. São Paulo: Atlas, 2003.

MARTINS, E.; ROCHA W. Métodos de custeio comparados: Custos e margens analisados sob diferentes perspectivas. São Paulo: Atlas, 2010.

MAZZUCO, M. A. S.; WRONSKI, P. G.; ZONATTO, V. C. da S. Custeio Baseado em Atividades e Tempo (TDABC): Um Estudo em uma Instituição de Ensino Superior do Sul do Estado de Santa Catarina. Anais... 2017. XXV Congresso Brasileiro de Custos, 2017.

MECCA, M. S.; FRANZOI, T. de F. M.; ECKERT, A.; BIASIO, R. Utilização do custo padrão como ferramenta de auxílio aos gestores na tomada de decisão. Anais... 2015. XXII Congresso Brasileiro de Custos, 2015.

Revista ENIAC Pesquisa, Guarulhos (SP), V.8, n.2, jul.- dez. 2019. 
NORONHA, D. P. Maricato J de M. Estudos métricos da informação: primeiras aproximações. Encontros Bibli. $1^{\circ}$ sem, 2008.

PROVENZANO, M.; CHEROBINI, M.; PESSIN, R. L.; SOUZA, A. de; MACHADO, D. G. Análise da percepção dos docentes quanto aos métodos baseados em atividades. Anais... 2016. XXIII Congresso Brasileiro de Custos, 2016.

RIBEIRO, Osni Moura. Contabilidade de Custos. São Paulo: Saraiva, 2009.

RICHARDSON, R. J. Pesquisa social: métodos e técnicas. São Paulo: Atlas, 1999.

ROSA, C.; CONDE, M. C. Custo-padrão e orçamento empresarial aplicado em culturas agrícolas temporárias. Anais... 2015. XXII Congresso Brasileiro de Custos, 2015.

SANCHES, A. K. D.; BRITTO, A. F. B.; SILVA, L. B. da S.; ARAÚJO, A. M. H. B.. Honorários Contábeis Calculados de Acordo com o Custeio por Absorção: Uma comparação com os valores efetivamente cobrados por um escritório de contabilidade no Distrito Federal. Anais... 2017. XXV Congresso Brasileiro de Custos, 2017.

SANTOS, W. J. L. dos; PADRONES, K. G. de S. A. Método de Custeio Baseado em Atividades para Educação Básica: uma proposta de aplicação. Anais... 2015. XXII Congresso Brasileiro de Custos. 2015.

SANTOS, K. V. D.; GADELHA, C. de A. P; LEITE, M. S. A. Viabilidade do método ABC para apoio a tomada de decisão em pequenos negócios. Anais... 2016. XXIII Congresso Brasileiro de Custos, 2016.

SANTOS, K. V. D.; OLIVEIRA, A. C. R. de; LEITE, M. S. A. O uso do método ABC para apoio a tomada de decisão em uma empresa do setor alimentício. Anais... 2015. XXII Congresso Brasileiro de Custos, 2015.

SCARDELATO, T. A.; PAVÃO, J. A.; CAMACHO, R. R. Integração Entre Gestão dos Custos da Qualidade e o Custeio Baseado em Atividades: Um Estudo no Setor de Controle de Qualidade em uma Empresa do Ramo de Laticínios. Anais... 2017. XXV Congresso Brasileiro de Custos, 2017.

SCHIER, Carlos Ubiratan da Costa. Controladoria: Como Instrumento De Gestão. $6^{\circ}$ ed. Curitiba: Juruá, 2008.

SCOTT, J. L. Stimulating awareness of actual learning processes. The Journal of the Operational Research Society, v. 53, n. 1, p. 2-10, jan. 2002.

SILVA, A. R.; POLICÁRIO S. M.; DEORCE, R. B. Aplicação do Método de Custeio Por Absorção com Departamentalização em um Salão de Beleza. Anais... 2017. XXV Congresso Brasileiro de Custos, 2017. 
SILVA, M. C. da; ANZILAGO, M.; TONIN, J. M. da F.; SCARPIN, J. E. Estudo Comparativo entre os Métodos de Custeio Absorção Aplicados na Produção do Milho no Estado do Mato Grosso. Anais... 2016. XXIII Congresso Brasileiro de Custos, 2016.

SILVA, E. R. S.; FRANCISCO, W. F. R.; CRUZ, D. B. da; BUENO, B. Custeio baseado em atividades: uma proposta do seu uso no contexto de uma Universidade Federal de Minas Gerais. Anais... 2016. XXIII Congresso Brasileiro de Custos, 2016.

SIQUEIRA, M. V.; MAZZIONI, S.; GOLLO, V.; KRUGER, S. D. Custeio por absorção x UEP: análise comparativa dos custos em uma indústria de confecções. Anais... 2016. XXIII Congresso Brasileiro de Custos, 2016.

SOUQUE, G. S.; MÜLLER, C. J. Sistema de Custeio para Comércio de Cervejas por meio de Beer Truck. Anais... 2017. XXV Congresso Brasileiro de Custos, 2017.

SOUZA, R. E. de; CASTANHA, E. T.; MONTEIRO, J. J.; MILANEZE, C. C.; CITTADIN, A. O uso do Custeio ABC para formação do preço de venda em um laboratório de análises ambientais. Anais... 2017. XXV Congresso Brasileiro de Custos, 2017.

SOUZA, R. M. de; COSTA, S. A. Complexidade Versus Viabilidade: Um Estudo de Caso Sobre $\mathrm{O}$ ABC em Ambiente de Estrutura Tecnológica Intensiva. Anais... 2015. XV Congresso USP de Controladoria e Contabilidade, 2015.

VICECONTI, P.; NEVES, S. Contabilidade de Custos: um enfoque direto e objetivo. 11. ed. São Paulo: Saraiva, 2013.

VICHINHESKI, K. A.; BENDLIN, L.; FERREIRA, R. R.; FERREIRA, J. P. Método de Custeio UEP - Unidade de Esforço de Produção: estudo de caso em uma indústria cerâmica do planalto norte catarinense. Anais... 2017. XXV Congresso Brasileiro de Custos, 2017.

VIEIRA, E. P.; SAUSEN, J. O.; SCHREIBER, R.; NORA, L. B. D. Custeio baseado em atividades da retaguarda operacional de uma instituição financeira. Anais... 2016. XXIII Congresso Brasileiro de Custos, 2016.

WEIS, A. D.; BALTHAZAR, D. B.; TRIERWEILlE, A.C. ANÁLISE DE CUSTOS: Um Estudo de Caso na Gráfica Alfa Ltda-ME. Anais..., 2008. II congresso UFSC de Controladoria e Finanças, 2008.

WERNKE, Rodney. Gestão de Custos: uma abordagem prática. 2. ed. São Paulo: Atlas, 2004.

XAVIER FILHO, J. L. J. Desenvolvendo tecnologia de gestão via pesquisa-ação: Uma forma alternativa de demonstrar o resultado tendo por base o custeio variável. Anais... 2015. XXII Congresso Brasileiro de Custos, 2015. 